\title{
Electrodeposited Gold Composite Coatings
}

\author{
MECHANISM OF FORMATION, MECHANICAL AND TRIBOLOGICAL PROPERTIES
}

\author{
Clive Larson \\ Editor, Gold Bulletin
}

\begin{abstract}
The special properties exbibited by electrodeposited composite coatings bave ensured industrial applications for them as a result of the high specification demands of modern technology. Recent advances in the understanding of the mechanism of formation of such coatings, including those involving gold matrices, and awareness of the properties of the latter, justify interest in their potential applications.
\end{abstract}

The past two decades have seen a steady increase in our knowledge and understanding, and most importantly our application of composite coatings formed by electrodeposition from aqueous suspensions of inert particles. A number of systems have progressed to the stage of having become completely accepted in high-technology industrial applications. These have evolved largely as a result of the improved wear resistance characteristics imparted by the composite coatings. Such applications have included the incorporation of silicon carbide particles into nickel electrodeposits on the contacting faces of Wankel engine housings (1), and cobaltchromium carbide composite coatings for high-temperature dry sliding wear in gas-turbine aeroengines $(2,3,4)$. E. C. Kedward (4) has reviewed research carried out in the field of electrodeposited composite coatings to 1973

It is, in fact, a measure of the understanding and appreciation of the properties which can be achieved by incorporating second phase particles into deposits that practical applications have also been found for electroless (autocatalytic) composite coatings. The inherent corrosion resistance of electroless nickel, its high hardness in the heat-treated form, and the fact that it can be deposited

Fig. 1 Effect of alumina content on the creep rate of electrodeposited goldalumina composites. As a result of the fineness of the particles $(0.02 \mu \mathrm{m}$ diameter) only a low volume percentage in the composite is required to improve creep resistance drastically. After (10)

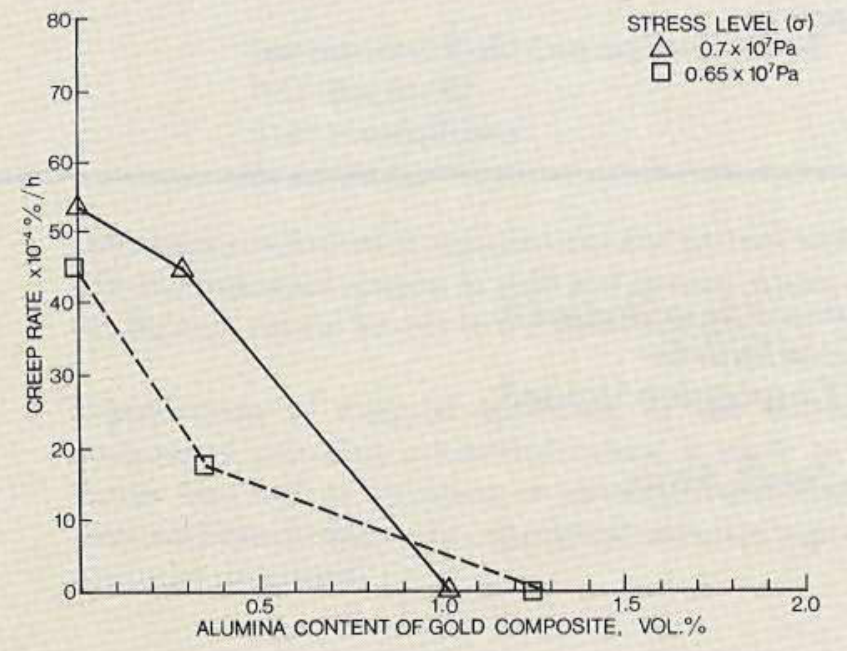

uniformly upon both the exposed and recessed surfaces of configurationally complex objects, combine with the tribological improvements afforded by codepositing such particles as silicon carbide or polytetrafluoroethylene (PTFE) to ensure its ready commercial utilisation (5-8). A recent paper by D.J. Kenton (9) in which the effects of different combinations of codeposited silicon carbide, calcium fluoride, alumina and PTFE on the abrasive wear, adhesive wear and sliding friction characteristics of electro less nickel are discussed, confirms the beneficial results previously reported.

In view of the above, it is perhaps surprising that gold-based electrodeposited composite coatings have not attracted more attention in industry in recent years. This review will therefore discuss present knowledge of the deposition of gold composites gained not only from work on such deposition, but also from studies of the electrodeposition of other metal composites. The mechanical and tribological properties of electrodeposited gold composite coatings which have been produced will also be reviewed.

\section{Gold Composite Coatings - Developments to date Alumina as the Dispersed Phase}

The earliest work published was that of F.K. Sautter $(10,11)$ who showed that it was possible to produce gold composite coatings by codeposition of alumina with gold from a buffered cyanide electrolyte containing the oxide in suspension.

The work carried out by Sautter was aimed at producing dispersion strengthened alloys, having creep rates lower than that of pure electrodeposited gold. His basic electrolyte had the following composition:

$\begin{array}{ll}\mathrm{KAu}(\mathrm{CN})_{2} & 10 \mathrm{~g} / 1 \\ \mathrm{Na}_{2} \mathrm{HPO}_{4} & 50 \mathrm{~g} / 1 \\ \mathrm{NH}_{4} \mathrm{H}_{2} \mathrm{PO}_{4} & \text { to give } \mathrm{pH} 6 \\ \mathrm{Al}_{2} \mathrm{O}_{3}(0.02 \mu \mathrm{m}) & 50 \mathrm{~g} / 1 \\ \text { Temperature } & 60^{\circ} \mathrm{C} \\ \text { Current density } & 0.5 \mathrm{~A} / \mathrm{dm}^{2}\end{array}$

Although he reported (10) that 'high oxide content' deposits were internally stressed, the compositions of the deposits were not given, except in the case of the samples from which the creep rate vetsus oxide content data were obtained. In these an oxide content of 1.25 volume per cent is the highest quoted. Sautter found that it was possible to obtain composites at high $\mathrm{pH}$ as well as at $\mathrm{pH} 6$ and since increasing the ion concentration by further addition of buffer salts to keep the $\mathrm{pH}$ value constant resulted in a decrease in 


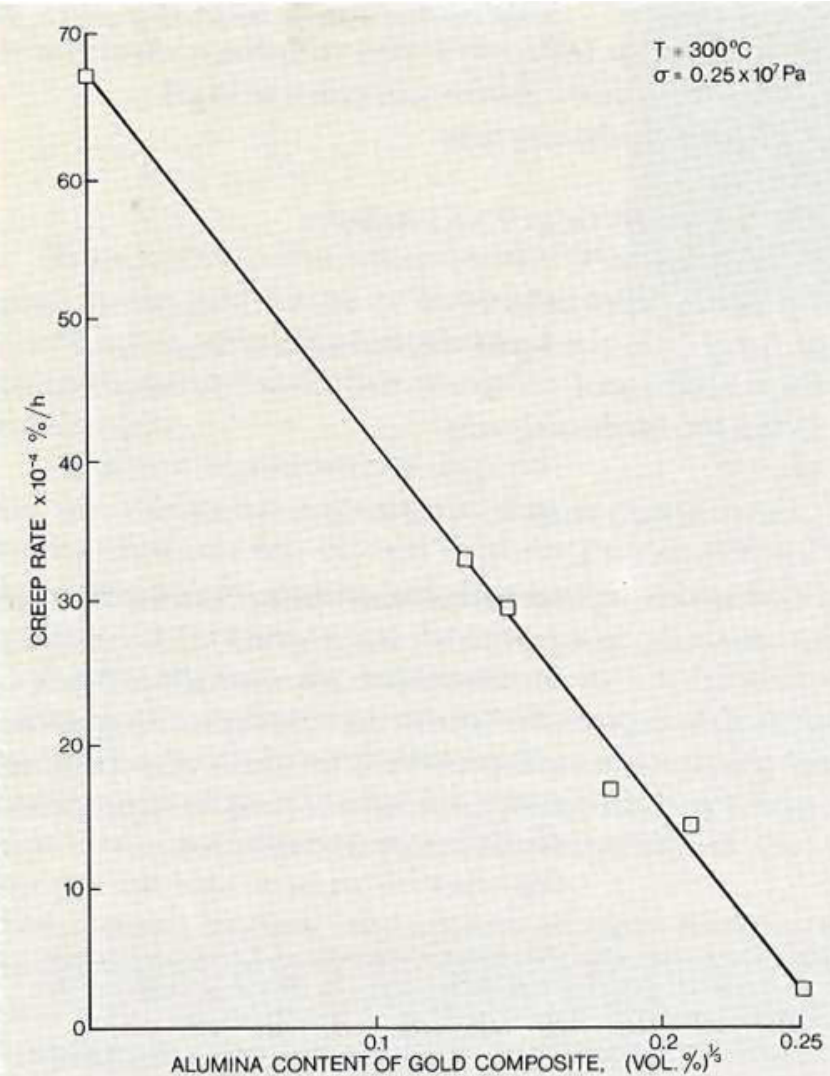

Fig. 2 Relationship of creep rate of electrodeposited gold-alumina composites with alumina content in the composites. After (11)
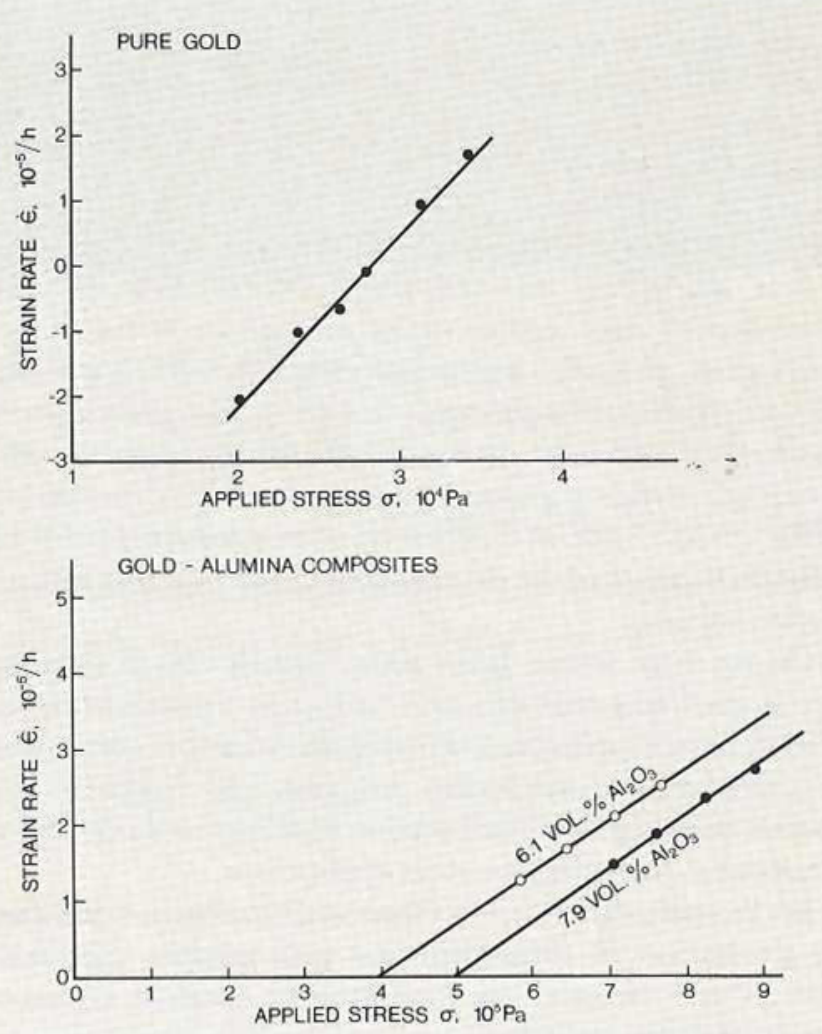

Fig. 3Stress-strain rate data for pure electroformed gold and two gold-alumina electroforms show the strengthening effect of the dispersed alumina. After (12b) the oxide content of the gold composite deposit, he concluded that the overall ion concentration plays a more significant role in the codeposition than the $\mathrm{pH}$. No simple relationship was observed between the plating conditions and the alumina contents of the deposits.

The presence of alumina in the electrodeposited gold had a marked beneficial effect on its creep rate and, under the test conditions (10), less than 1.25 volume per cent of the $0.02 \mu$ m oxide particles was required to reduce the creep rate to zero (Figure 1). Later(11) an inverse linear relationship was shown to exist between the creep rate and the cube root of the alumina content of the deposits (Figure 2)

Electrical resistivity, it was claimed, was not affected by incorporation of alumina, the recorded values being of the same order as that expected for electrodeposited gold. However, the range of alumina contents over which this was so was not quoted.

Chen and Sautter (12) measured the porosity of electrodeposited gold-alumina composites, before and after heat-treatment for $1 \mathrm{~h}$ at $1000^{\circ} \mathrm{C}$ in air, by accurate measurement of deposit density. The composites were electrodeposited at $60^{\circ} \mathrm{C}$ and a current density of $0.35 \mathrm{~A} / \mathrm{dm}^{2}$ from an alkaline cyanide solution at $\mathrm{pH} 10.5$ containing

$$
\begin{array}{ll}
\mathrm{KAu}(\mathrm{CN})_{2} & 10 \mathrm{~g} / \mathrm{l} \\
\mathrm{KCN} & 10 \mathrm{~g} / 1 \\
\alpha-\mathrm{A} 1_{2} \mathrm{O}_{3}(1 \mu \mathrm{m}) & 2-25 \mathrm{~g} / 1
\end{array}
$$

The deposits were grown to a thickness of $180 \mu \mathrm{m}$ in the shape of a tube, and removed from the copper substrate for testing. Contents of up to 10.5 volume per cent of $1 \mu \mathrm{m}$ alumina were found in the gold composites.

The same two authors have described studies of the surface and interfacial energies of composites (12b) produced by the same electrolyte and alumina powder as those described in (12). These revealed that at very high temperatures, in addition to other strengthening mechanisms, the effects of the energy associated with the interface and, to a lesser extent, the influence of surface and grain boundary energies must be overcome before gold-alumina alloys will deform plastically. Figure 3 shows the marked difference in the variation of strain rate with stress during creep testing at $950^{\circ} \mathrm{C}$ of tubular electroformed gold composite specimens of $40 \mu \mathrm{m}$ wall thickness containing 6.1 and 7.9 volume per cent alumina, compared with similar data obtained during tests on specimens of pure electrodeposited gold. 
The most recent publication found on particle codeposition with gold is a paper by C. Buelens and his colleagues which discusses the mechanism of formation of composite deposits, and that of goldalumina and copper-alumina in particular (21). This work will be discussed later in this review.

\section{Solid Lubricant as the Dispersed Phase}

Not all of the development work carried out with electrodeposited gold composites has involved the codeposition of hard ceramic particles. Organic polymers such as PTFE have also been codeposited as the dispersed phase with gold to give composite coatings (13). Although the use of such coatings appeats to offer advantages in sliding contact situations as a result of the very low coefficient of friction of codeposited polymers such as PTFE the author is unaware of the development of practical uses for such products to date.

On the same theme as the above, namely that of reducing friction at a sliding surface by the introduction of solid lubrication, a French patent application (14) has claimed that the codeposition of sulphides of molybdenum, niobium and tungsten with electrodeposited gold yielded deposits with improved tribological behaviour in some sliding contact applications.

In a Russian patent (15) A.G. Filatov and his colleagues described the production of electrodeposited gold-graphite composite coatings and reported on the improved abrasion resistance properties shown by them.

A more recent, 1982, patent publication (16) describes the improvements in abrasion resistance and reduced sticking obtained in gold electrical contact surfaces by codepositing particles of solid lubricants such as graphite, and the sulphides and selenides of molybdenum, tungsten, niobium and tantalum with gold. The lubricant is added in concentrations of preferably 50 to $150 \mathrm{~g} / \mathrm{l}$ to either acid or alkaline conventional gold electrolytes and electrodeposition carried out under notmal conditions, but with heavy agitation. The deposits described are claimed to be suitable for use in relay contacts, sliding contacts and slip rings.

\section{Carbide and Metallic Particles as the Dispersed Phase}

H.R. Peiffer $e t a l$. prepared gold-tungsten carbide composite electrodeposits and tested these in reed switch and certain relay applications. The incorporation of tungsten carbide in the gold matrix was shown to have a significantly beneficial effect on welding and metal transfer in these applications (17). Wear-resistant gold composite coatings have also been reported in which fine diamond particles were codeposited with gold (18).

The production of gold composite electrodeposited coatings and their physical and tribological properties have also been studied at the Fulmer Research Institute by the author (19, 22). Gold composites were formed by codeposition of metallic particles, in particular chromium, or of titanium and tungsten carbides. Two proprietary gold plating baths based on different gold complexes were used, namely:

(1) An acid cyanide bath:

$\mathrm{KAu}(\mathrm{CN})_{2}$ to give a gold concentration of $10 \mathrm{~g} / \mathrm{l}$

Buffer and conducting salts

$\mathrm{pH} 5.5$

Current density range $0.5-1 \mathrm{~A} / \mathrm{dm}^{2}$

Temperature $60^{\circ} \mathrm{C}$

(2) An alkaline sulphite bath:

$\mathrm{M}_{3} \mathrm{Au}\left(\mathrm{SO}_{3}\right)_{2}$ to give a gold concentration of $10 \mathrm{~g} / \mathrm{l}$

$(\mathrm{M} \equiv$ alkali metal)

Buffer and conducting salts

$\mathrm{pH} 9.5$

Current density range $0.3-0.6 \mathrm{~A} / \mathrm{dm}^{2}$

Temperature $60^{\circ} \mathrm{C}$

Good quality deposits were obtained using both the bath agitation methods (plate pumper and continuous circulation), described in (3) - the former is shown schematically in Figure 4. Analysis of the deposits showed that the volume percentage of dispersed phase present was dependent on the nature of the particles, the type of gold electrolyte, the volume of particles suspended in the bath, the plating current density, and agitation.

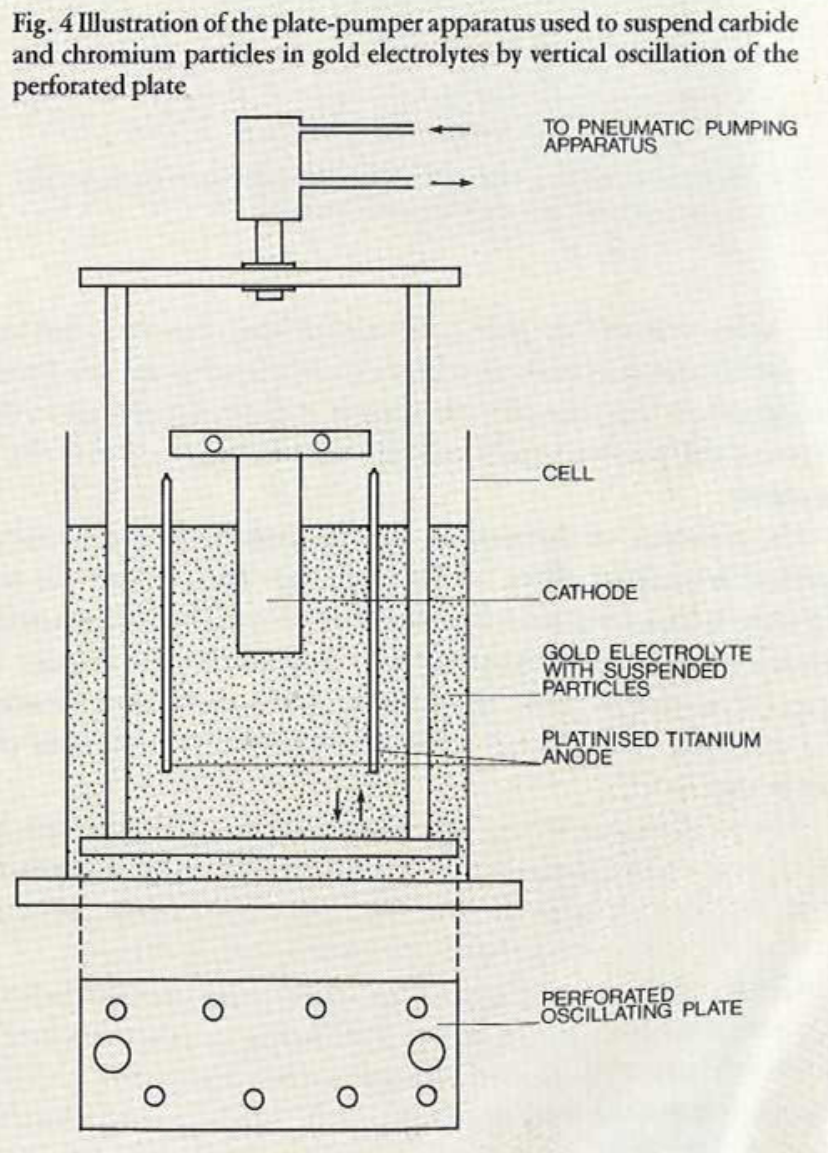


Fig. 5 Typical gold-chromium composite electrodeposit formed in an alkaline gold sulphite solution. After (22)

$\times 1000$

Figure 5 shows in cross-section a typical good quality gold-chromium composite electrodeposit, containing 17.5 volume per cent chromium, produced from an alkaline sulphite bath.

Significant improvements in the physical and tribological properties of electrodeposited gold were brought about by incorporation of a dispersed phase, and these will be discussed later in this review.

Further work on the advantages of codepositing metallic and cetamic particles with gold, particularly in wear situations involving electrical contacts, has been described in two Japanese patents (20). In

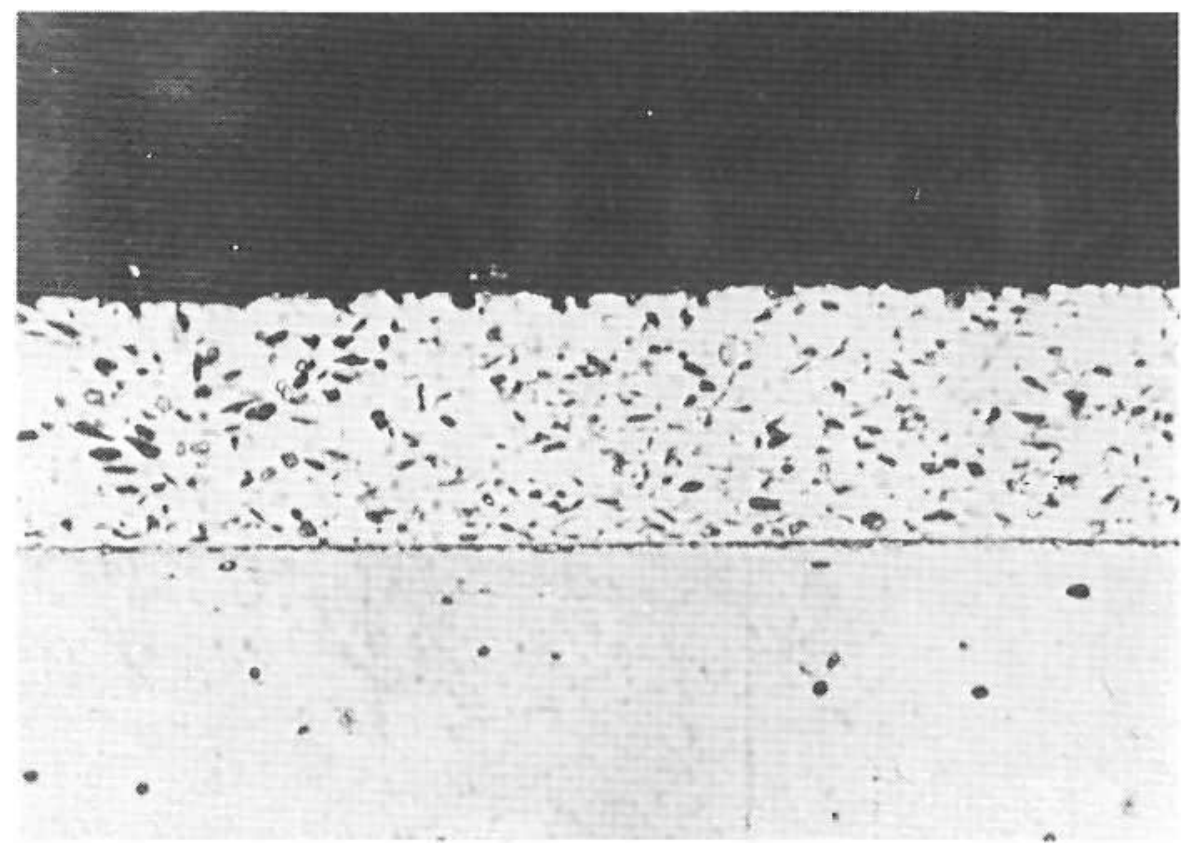
the one case hard metal particles selected from thenium, rhodium, cobalt, chromium, molybdenum or nickel were dispersed in a gold or gold alloy electrolyte and composite coatings having improved wear resistance and service life in relay contact applications were produced. For example, the formation is described of electrodeposited gold - rhenium coatings containing 4 weight per cent rhenium from a bath containing $20 \mathrm{~g} / 1$ powder, and operated at $0.5 \mathrm{~A} / \mathrm{dm}^{2}$ and a temperature of $25^{\circ} \mathrm{C}$.

The second patent claims improved performance and service life in relay contacts, of composite gold coatings containing nitrides, oxides, borides or carbides of titanium or zirconium. Thus a gold coating containing 3 weight per cent $\mathrm{TiB}_{2}$ was formed under the conditions described above and tested as a relay contact surface. Both this and the gold-rhenium deposit above were claimed to give a relay contact service life of about $10^{6}$ on-off cycles under the test conditions compared with a life of $1.2 \times 10^{5}$ such cycles in the absence of the dispersed phase.

\section{Factors Affecting Particle Codeposition}

A review of the literature confirms that electrolytic codeposition of particles with gold depends on the same operating parameters and electrochemical effects as have been shown to affect the extent of dispersoid incorporation in other electrodeposited metals such as nickel, copper and cobalt.

Thus, the mass transport effect on codeposition is observed in the relationship between volume fraction of dispersoid incorporated and concentration of powder in the gold electrolyte. The volume percentage $\left(\mathrm{V}_{\mathrm{p}}\right)$ of titanium and tungsten carbides codeposited with gold has been reported (19) to follow an approximately parabolic relationship with carbide powder concentration $(C)$ in the

solution:

$$
\mathrm{V}_{\mathrm{p}}{ }^{2} \alpha \quad \mathrm{C}
$$

whereas this was not so readily apparent with incorporation of chromium powder in gold (22).

In both cases, however, the same tendency is exhibited. A rapid increase in codeposition occurs as the concentration of powder in the bath is increased from zero, followed by a slowing down of the codeposition rate as the bath is further loaded with dispersoid. This continues until a limit is reached, above which increase in the concentration of the dispersed phase in the bath does not significantly alter its concentration in the deposit. Figures 6(a) and (b) illustrate the relationships between the concentrations of the disperse phase in the electrolyte and in the deposits as obtained for deposition of gold-carbide and gold-chromium. In addition to showing the effects of varying the plating current density and the rate of agitation of the bath on the rate of incorporation of the dispersed phase, Figure 6 further illustrates the selective nature of the particle codeposition and the dependence of rate of incorporation of dispersoid on the nature of the electrolyte and the nature of the dispersoid itself.

Thus, it has been noted (19) that the ease of codeposition of carbides with gold decreases as follows:

Alkaline gold sulphite - titanium carbide

Acid gold cyanide - tungsten carbide Alkaline gold sulphite - tungsten carbide Acid gold cyanide - titanium carbide $\downarrow$ of particles

The ease with which chromium powder codeposits with gold from an alkaline sulphite electrolyte is midway in the above series. 


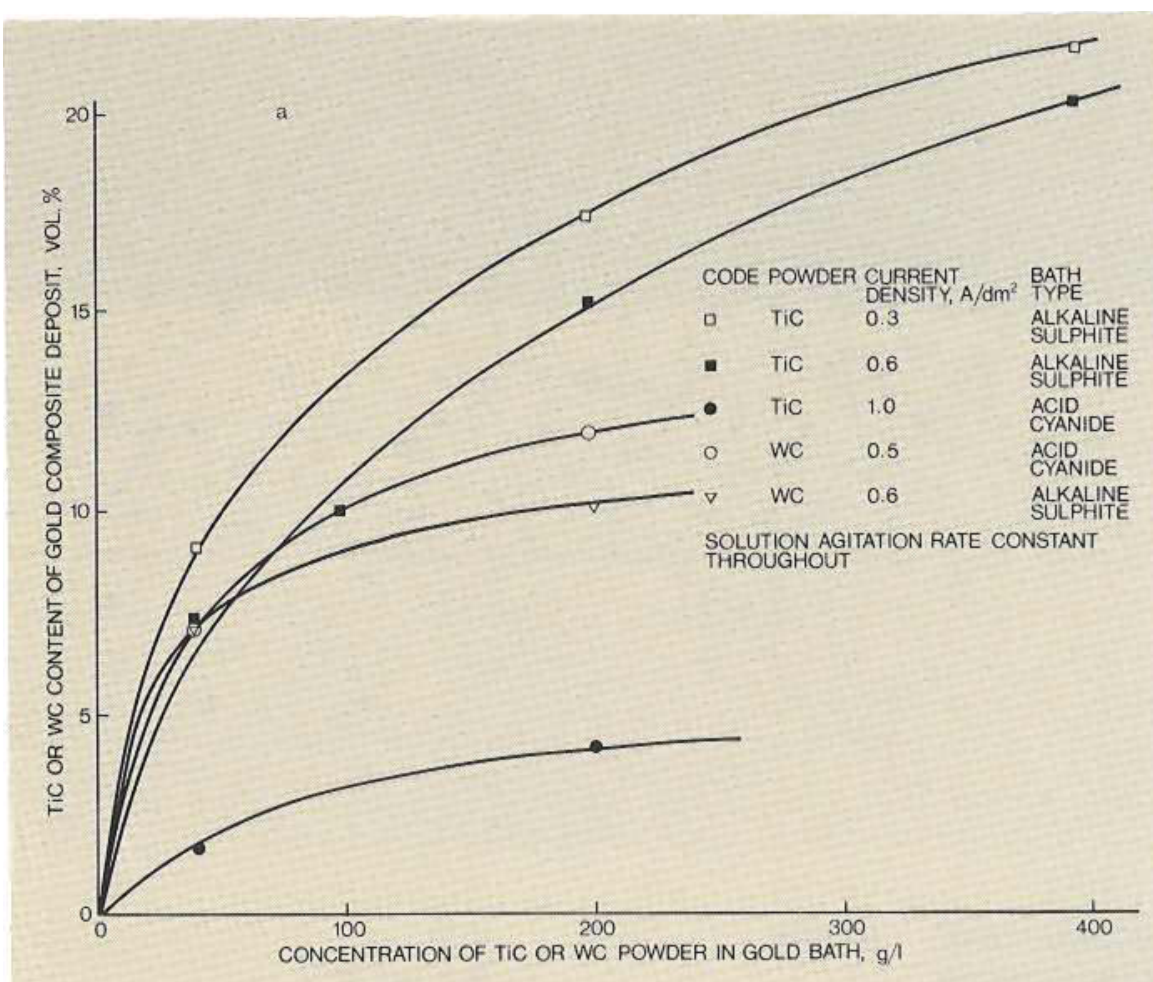

Fig. 6 Dependence of percentage of dispersoid incorporated in electro-

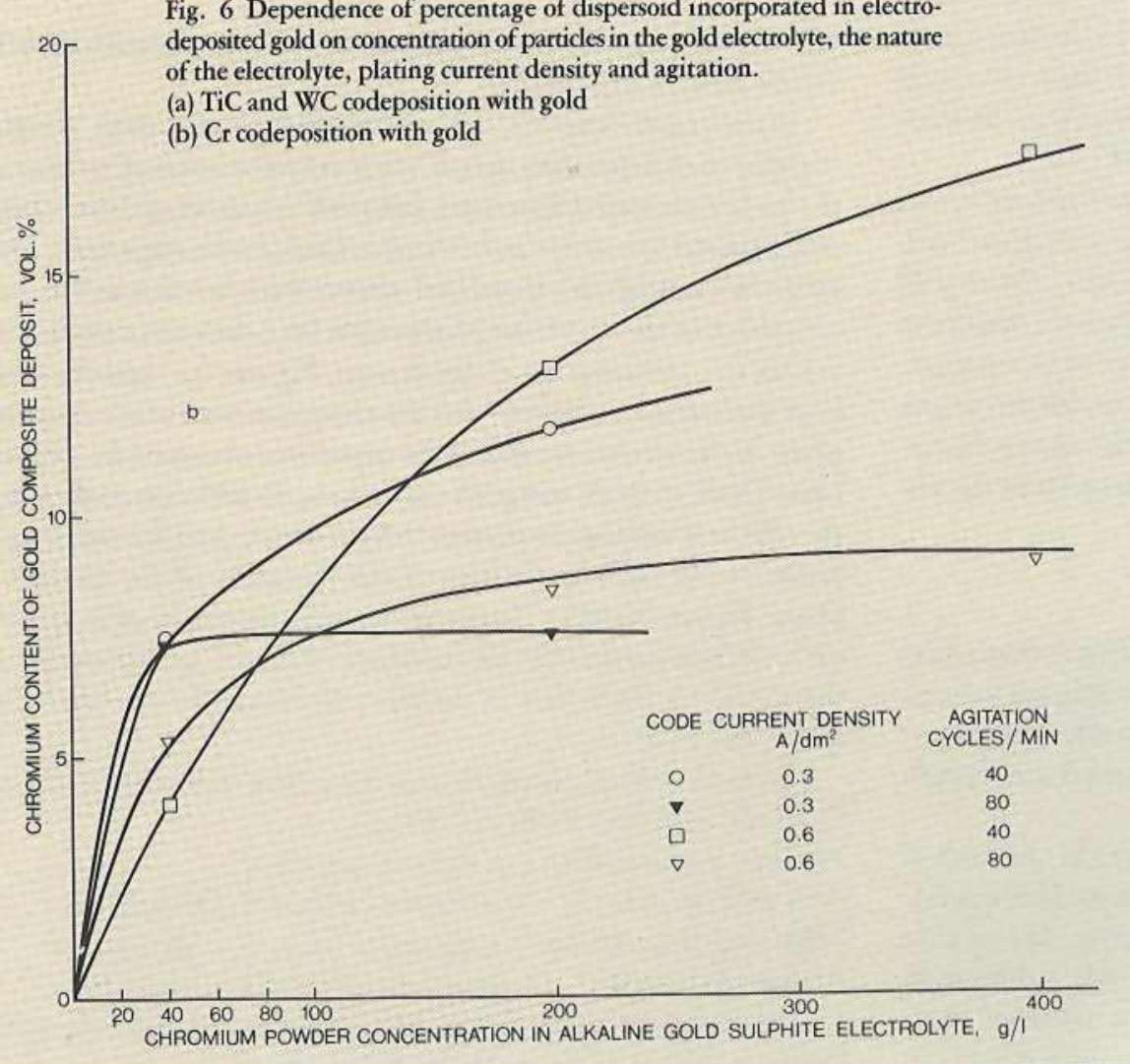

The dependence on the composition (ionic) of the bath and on the nature of the dispersoid is strong supporting evidence for theories recently put forward to explain the codeposition of particles. These theories postulate charging of the particlessuspended in the bath through adsorption of ions on their surfaces, and subsequent reduction of these at the cathode as the rate controlling step in the process.

\section{Mechanism of Codeposition}

It has become widely accepted in the past decade that the frequency of collision of particles with the cathode surface, which depends upon the concentration of dispersed particles in an electrolyte, is not the major parameter affecting the rate or extent of incorporation of dispersoids. It is apparent that the existence of a positive charge at the interface of a particle surface and the electrolyte is important in attracting the particle to the cathode surface and holding it there during the critical time (of the order of 100 seconds for a $1 \mu \mathrm{m}$ particle in a normal gold electrolyte) required for sufficient matrix to deposit around the dispersoid to mechanically key it in position. The feasibility of achieving this for any given particle and plating system has not been obvious.

Thus alumina has been found to codeposit from both acid and alkaline gold cyanide baths but alumina will not codeposit from alkaline silver solutions (10).

It has been found that alumina will codeposit with copper teadily from a cyanide bath (23) but not from an acid sulphate bath $(23,24,25)$. However, the same powder is reported to codeposit easily with nickel $(23,26,27)$ and iron (28) from acid sulphate baths. Addition of monovalent cations, particularly thallous ions $(24,25)$, and to a lesser extent alkali metals, encourages codeposition of alumina from acid copper sulphate baths.

Chen et al. (24) have also found that, with or without additon agents, the correct crystalline form of alumina (hexagonal- $\alpha$ rather than spinel-type cubic- $\beta$ ) is required for satisfactory codeposition with copper. 
Guglielmi (29) has claimet that in nickel sulphamate electrolytes, codeposition of silicon carbide is increased by increase in current density but that of titania is decreased.

It is now generally agreed that the mechanism by which codeposition with a metal of particles suspended in a plating bath takes place consists of basically two processes. First hydrodynamic flow conditions cause movement of particles to the cathode region. Secondly adsorption of the particles, the surfaces of which carty adsorbed cations, occurs through the diffusion layer and on to the cathode surface. The particles are then held at this surface long enough for sufficient metal deposit growth to occur in order for them to be embedded.

Guglielmi (29) considered that the adsorption process consisted of two steps, the first of which was the creation of a weak, essentially physical, bond between the cathode and the particles which were surrounded by adsorbed layers of ions and solvent molecules. The second step was postulated to be a field-assisted adsorption process in which the loosely attached solvent molecules were removed, the adsorbed ions were reduced and permanent attachment to the cathode surface occurred.

Other research published at about the same time, and since Guglielmi put forward this hypothesis, has confirmed that adsorption of ions on to suspended particles to create a positive surface charge upon them plays an important role in determining (a) whether significant codeposition occurs and (b) the amount of codeposition which takes place.

Thus Snaith and Groves (30) used streaming potential and later (32) streaming current measurements to determine the zeta potential and surface charge density for different ceramic particles in an acid copper sulphate solution. They concluded that the surface density on the particles undergoes a polarity change from negative to positive as electrolyte concentration is increased. Further concentration increase to that of approximate plating bath strength caused a proportionate increase in positive charge density. It was suggested that this was due to adsorption of cations on the surface of the particle.

Foster and Kariapper $(31,33)$ have confirmed by streaming potential and adsorption studies that the building up of positive charge on the surface of particles is necessary for codeposition to occur, and have shown that nickel and copper ions adsorb on particles suspended in the relevant electrolytes. The mass of ions adsorbed was found to depend on the solution molatity. These authors also studied the effects of current density and agitation of suspension of the volume fraction of particles incorporated, and noted that these effects diminished as the concentration of powder in the electrolyte was increased. They also confirmed the important work by Tomaszewski et al. (25) that addition of selected cations in this case thallium and rubidium - can 'promote' codeposition of particles by increasing surface charge density.

Tomaszewski (34) has also shown that the presence of different anions in a plating solution can depress the rate of codeposition of particles suspended in the bath, the most serious effect being shown by chloride ions. However, addition of specific multivalent cations to such solutions dramatically increases the adsorption of metal ions on to the particle surfaces, and also the rate of codeposition.

Following on from the research described above and from research carried out in their own laboratories on the mechanism of codeposition of alumina with copper and nickel (35), C. Buelens et al. have recently published the results of a study of the electrochemical aspects of codeposition of $\gamma$-alumina with gold and copper from acid cyanide and sulphate electrolytes respectively (21).

The main conclusion from this work is that the mechanism of codeposition of alumina with both copper plated from the highly acid sulphate solution, and gold deposited from an additive-free bath containing $10 \mathrm{~g} / \mathrm{l}$ gold as $\mathrm{KAu}(\mathrm{CN})_{2}$, and buffered by $100 \mathrm{~g} / \mathrm{l}$ potassium dihydrogen phosphate to $\mathrm{pH} 4$, is the same. In agreement with the results of other researchers in this field, Buelens et al. confirm that the reduction of ions adsorbed on the codepositing particles appears to be the rate-determining step in the codeposition process. The adsorbed species is thought to be a gold cyanide complex formed, perhaps, in the following steps suggested (36) as those involved in the reduction of the $\mathrm{Au}(\mathrm{CN})_{2}$ ion to metal in the electrodeposition of gold from cyanide solutions:

(a) $\mathrm{Au}(\mathrm{CN})_{2}^{-} \rightarrow \mathrm{Au}(\mathrm{CN})+\mathrm{CN}$

which occurs in the cathode diffusion layer with the reaction product $\mathrm{Au}(\mathrm{CN})$ being either adsorbed or forming an insoluble film at the cathode, and

(b) $\mathrm{Au}(\mathrm{CN})+\mathrm{e}^{-} \rightarrow \mathrm{Au}+\mathrm{CN}^{-}$

Buelens et al. found that the amounts of alumina codeposited reached maxima at certain applied overpotentials. This relationship has been ascribed to the reduction of different adsorbed gold complex species at these overpotentials. The results of this work have been shown to be quite consistent with a 2-step codeposition mechanism of adsorption of ionic species on particles, and adsorption of particles on the cathode.

\section{Electrodeposited Gold Composite Properties}

The most comprehensive data obtained on the physical and tribological properties of gold composite electrodeposits have been obtained from creep tests on gold-alumina $(10,11,12)$ and hardness, tensile strength and sliding wear results on gold-tungsten carbide and gold-titanium carbide coatings (19, 22). However, from these data an overall picture of the benefits conferred upon gold electrodeposited surfaces by incorporating a dispersed phase can be obtained.

The drastic improvement in creep resistance afforded by codepositnng small volume fractions of very fine alumina $(0.02 \mu \mathrm{m}$ diameter) with gold is illustrated in Figures 1 and 2 . When viewed in the light of the amount of oxide incorporated the sharp drop in creep rate reported may appear to be unusually large. However, on calculation of the average interparticle spacing in such composite 
deposits by the volumetric model developed by Meiklejohn and Skoda (37):

$$
\begin{aligned}
\mathrm{D}_{\mathrm{p}} & =\frac{0.82 \mathrm{~d}}{\mathrm{~V}_{\mathrm{p}}^{1 / 3}} \\
\text { where } \quad \mathrm{D}_{\mathrm{p}} & =\text { centre }- \text { centre interparticle separation } \\
\mathrm{d} & =\text { average particle diameter } \\
\mathrm{V}_{\mathrm{p}} & =\text { particle volume fraction in composite }
\end{aligned}
$$

it can be seen that for $0.02 \mu \mathrm{m}$ particles the average distance between centres can be calculated at $0.08 \mu \mathrm{m}$ - which means surface - surface interparticle spacing of only $0.06 \mu \mathrm{m}$, yielding likely dispersion-strengthening conditions.

In Figure 3 the relationship given between applied stress and strain rate shows that impressive strengthening is achieved by codepositing alumina particles of diameter $1 \mu \mathrm{m}$ at higher contents ( 6.1 and 7.9 volume per cent).

Microhardness measurements were made on metallographic cross-sections of composite gold-carbide and gold-chromium specimens $(19,22)$ in both the as-deposited and annealed states, and tensile tests were carried out at ambient and elevated temperatures. Preliminary sliding wear and contact resistance measurements were carried out using an apparatus in which the gold composite electrodeposits were produced on cylindrical specimens which were mounted and totated against hard gold alloy wires under variable load ing. Other wear tests, particularly those involving gold-carbide composites, were carried out with the well-documented pin-and-disc type of tribometer, shown schematically in Figure 7, using hard gold alloy wire pins rubbing under $100 \mathrm{~g}$ loading against a rotating composite plated disc.

The hardening effect obtained by incorporating hard particles into an electrodeposited gold matrix is illustrated by Figure 8 in which the relationship between the Vickers hardness ( $25 \mathrm{~g}$ load) of a deposit cross-section and the percentage of titanium carbide in the gold is shown. Although the improvement in hardness obtained is considerable, such deposits were sufficiently ductile to strip from the substrates and use as tensile strength test specimens (19).

Sliding wear data obtained from the pin-and-disc tribometer tests have shown that the wear volume obtained for electrodeposited gold is reduced when carbide particles are codeposited, for all combinations of particle composition and bath type (Figure 9). The wear volume of the deposits was estimated by measurement of the track width and depth using an optical microscope equipped with a vernier focus.

Plotting the gold composite wear resistances, obtained by calculating the reciprocal of the estimated wear volumes shown by the gold - carbide deposits illustrated in Figure 9, against the carbide particle separation distances, calculated from equation 3 above, indicates (Figure 10) that meaningful improvement in sliding wear resistance may occur with particles of this size ( $1 \mu$ m diameter) only at volume fractions sufficiently high to yield interparticle distances of less than about 3 times the particle size.

It would be expected that the incorporation of smaller particles would result in improved wear resistance at correspondingly lower volume fractions of codeposited material. Further research into this particular aspect of electrodeposited gold composites would appear to hold promise of beneficial results.

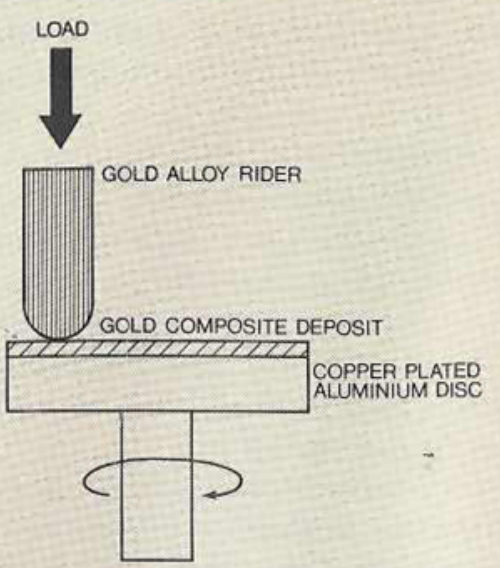

Fig. 7 Schematic representation of pin-anddisc tribometer used for determining sliding wear resistance of gold-TiC and gold-WC deposits described in this review, the data from which being illustrated in Figures 9 and 10

Fig. 8Effect of TiC content of electrodeposited gold-TiC composites on the Vickers microhardness of the deposits obtained from both alkaline gold sulphite and acid gold cyanide solutions

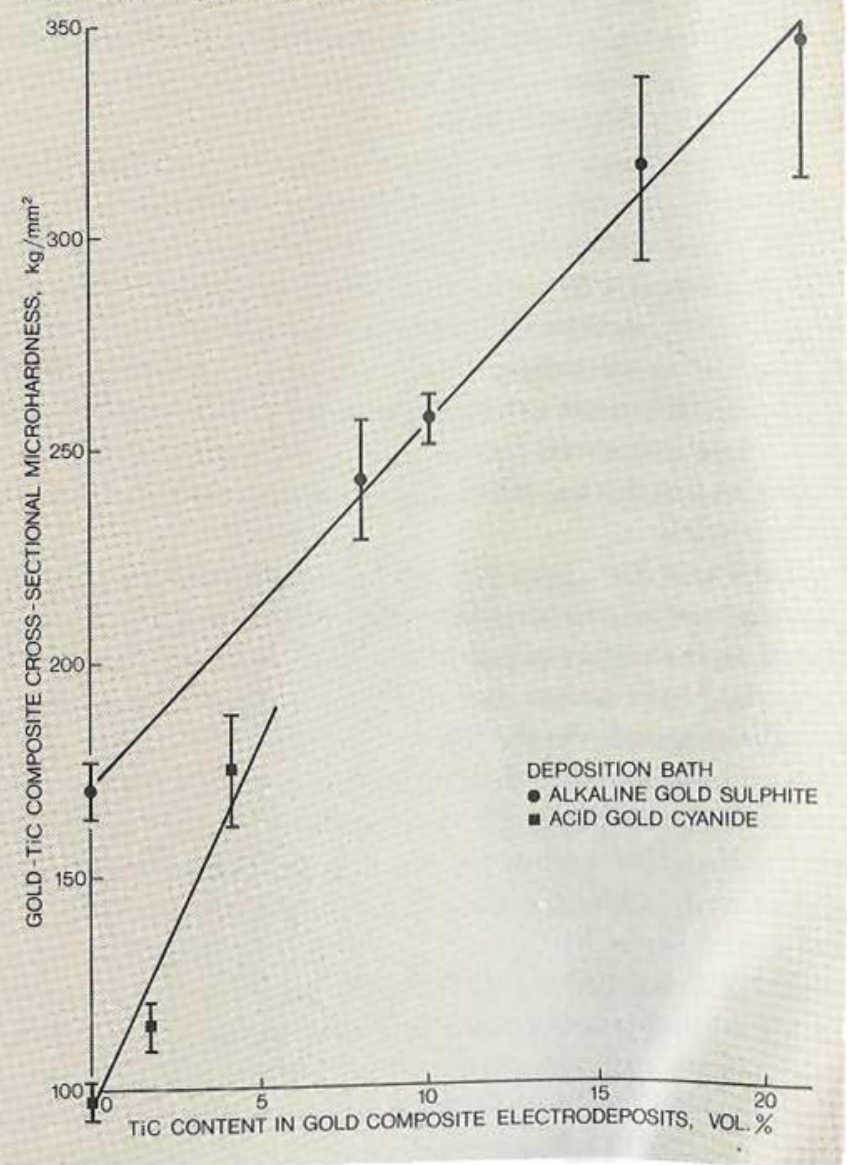




\section{Concluding Remarks}

Our knowledge and understanding of the mechanism of formation of electrodeposited gold composites has been reviewed both in the light of the work published on them and by extrapolation of the data obtained in studies of the electrodeposits and properties of composites with other metals. The most probable mechanism by which these composites form involves adsorption of ionic species

Fig. 9 Relationship between sliding wear volume and carbide content of electrodeposited gold-carbide composites in contact with hard gold alloy rider under a $100 \mathrm{~g}$ load, after $10^{5} \mathrm{~cm}$ track sliding in repeat pass mode
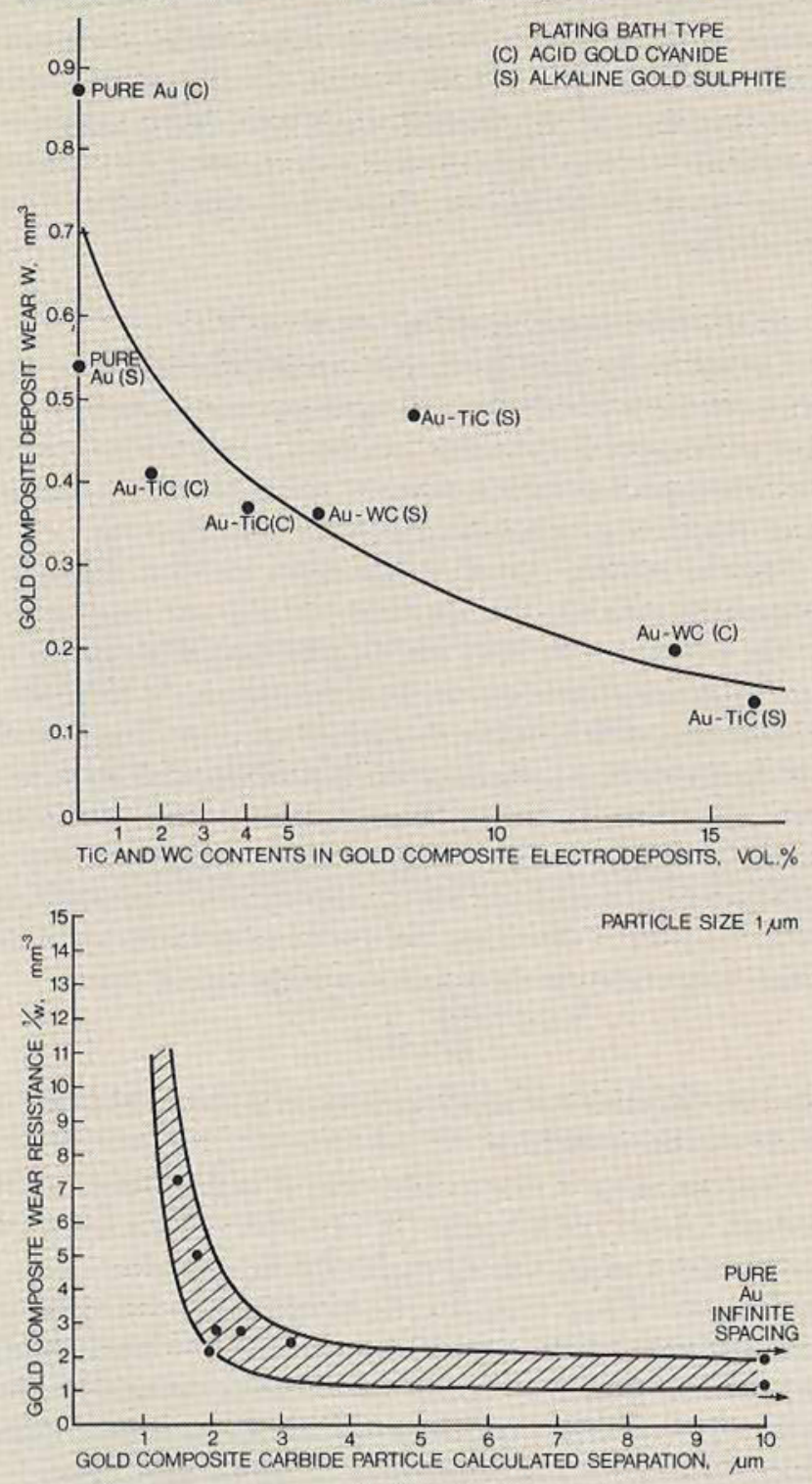

Fig. 10 Sliding wear resistance of gold and gold composite electrodeposits illustrated in Figure 9 as a function of the calculated interparticle separation (particle diameter $1 \mu \mathrm{m}$ ) on the sutface of the particles in the plating bath, diffusion of the charged particles through the cathode layer, reduction of the adsorbed ions and strong adsorption of the particles to the cathode surface.

Work on the production and properties of electrodeposited gold composites has been somewhat limited to date.

Nevertheless it has been demonstrated that certain properties of electrodeposited gold can be significantly modified through codeposition of finely divided particles of various materials with the metal. Particular attention has been given so far to the modification by this means of such properties as hardness, creep rate, tensile strength and sliding wear resistance. The potential for further developments in this field merits consideration.

\section{References}

1 N.S.U., U.K. Pat. $1200410(1970)$

2 U.K. Min. Def., Proc. Spec. D.T.D. $943(1974)$

3 E.C. Kedward, K.W. Wright and A.A.B. Tennett, Tribology Internat, 1974 Oct., 221-227; E.C. Kedward, C.A. Addison and A.A.B. Tennett, Trans. Inst. Metal Finish., 1976, 54, (1), 8-16

4 E.C. Kedward, Cobalt, 1973, 3, 53-59 and 66

5 K. Parker, U. S. Pat. 3,723,078 (1968); U.K. Pat. 1310921 (1970)

6 W. Metzger, U.S. Pat. 3,753,776(1970)

7 F.N. Hubbell, Plat. Surf. Finish., 1978, 65, (12), 58-62

8 K. Parker, Plating, 1974, 62, (9), 834-841

9 D.J. Kenton, J. Powder Metall. Powder Technol., 1983 19, (3), 185-195

10 F.K. Sautter, 'Electrodeposition of Dispersion - Strengthened Au- $\mathrm{A}_{2} \mathrm{O}_{3}$ Alloys', Watervlief Arsenal, N.Y., Tech. Rep. WVT-RR-6321, 1963

11 F.K. Sautter, Metall., 1964, 18, 596-600

12 E.S. Chen and F.K. Sautter, J. Electrochem. Soc., 1970, 117, 726-728

12b F.K. Sautter and E.S. Chen, in 'Proc. Metall. Soc. Conf. Vol. 47, 1968', pp. $495-508$

13 N.V. Akzo, Neth. Pat. Appl. 72 03,718 (1973)

14 Centres Stephanois de Recherche Mécanique Hydromecanique, French Demande 2,081,283 (1972)

15 A.G. Filatov et al., Russ. Pat. 301,373 (1971)

16 Siemens A.G., German Offen. 3032469 (1982)

17 H.R. Peiffer, J.E. Marley, R.J. Kobler and W. Jacobs, in 'Proc. 17th Ann. Nat. Relay Conf.,' Oklahoma State Univ., 1969, p.1.

18 Ernst Winter and Sohn., U.K. Pat. 1391001 (1975)

19 C. Larson, Gold Bull., 1975, 8, (4), 127-130; see also Composites, 1976 (Jan.), 9-11 and Galyano-Organo, 1979, 79, (Mar.), 175-178

20 Matsushita Electric Works Itd., Japanese Prelim. Publ. 04433 (1977) and $04434(1977)$

21 C. Buelens, J.P. Celis and J.R. Roos, J. Appl. Electrochem., 1983, 13, (4) $541-548$

22 C. Latson, Fulmer Research Institute Report R366/5, June 1973; R366/6 March 1974; R366/7 October 1974 (with M.A.R. Baig)

23 E.A. Brandes and D. Goldthorpe, Metallurgia, 1967, 195

24 E.S. Chen et al., Metall. Trans., 1971, 2, 937

25 T.W. Tomaszewski, L.C. Tomaszewski and H. Brown, Plating, 1969, 56, 1234

26 F.K. Sautter, J. Electrochem. Soc., 1963, 110, 557

27 V.P. Greco and W. Baldauf, Plating, 1968, 55, 250

28 D.S.R. Brown and K.V. Gow, Plating, 1972, 59, 437

29 N. Guglielmi, J. Electrochem. Soc., 1972, 119, 1009

30 D.W. Snaith and P.D. Groves, Trans. Inst. Metal Finish., 1972, 50, 95

31 J. Foster and A.M.J. Kariapper, Trans. Inst. Metal Finish., 1973, 51, 27-31

32 D.F. Snaith and P.D. Groves. Trans. Inst. Metal Finish., 1977, 55, 136-140

33 A.M.J. Kariapper and J. Foster, Trans. Inst. Metal Finish, 1974, 52, 87-91

34 TW. Tomaszweski, Trans. Inst. Metal Finish., 1976, 54, 45-48

35 J.R. Roos, J.P. Celis and J.A. Helsen, Trans, Inst. Metal Finish., 1977, 55, $113-116$

M.J. Bhagwat, J.P. Celis and J.R. Roos, Trans. Inst. Metal Finish., 1983, 61, $72-79$

$36 \mathrm{~N}$. Ibl and M. Angerer, J. Appl. Electrochem., 1979, 9, 219

37 W.H. Meiklejohn and R.E. Skoda, Acta Metall., 1959, 7, 675 